\title{
Simulation method for determination of human reliability function taking stress into consideration
}

\author{
Mieczysław Hann, Prof. \\ Szczecin University of Technology
}

\begin{abstract}
Application of computer simulation method for determination of the reliability function of a human being treated as an element of the system was presented in the paper. A method of considering the influence of the incidental random events occurring in the technical system or surroundings on committing faults by a human in the condition of stress was discussed.

Computer code and examples of the results were also presented.
\end{abstract}

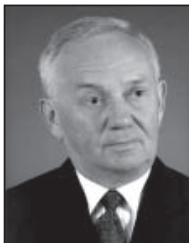

Keywords: human factor, reliability, computer simulation

\section{INTRODUCTION}

Macrosystem human-being - technology - marine environment is considered in the analysis of reliability and safety seeking the probability of appearance of a damage eventually followed by the accident.

Groups of functions performed by human can be distinguished in operations of machinery and marine systems similarly to the other branches of technology. Typically, the groups are:

is crew (seaman, steersman, carpenter etc.)

is supervisors (captain, officer, boatswain, inspector, insurance agent, owner)

is operator (of crane, decompression system, drilling system etc.)

is worker (diver, borer, assembler, underwater welder etc.).

Features of a human as an element of the macrosystem are difficult to define due to individual differences and complex external influences. The problem is addressed to e.g. in [3, 9, $14,15,17]$.

In the present paper an attempt is made to estimate analytically the influence of the technical system and marine environment on the human reliability in the aspect of the stress arising in the conditions of threat being the result of random events occurring in the technological system and environment.

In the human reliability analysis it is necessary to treat the surroundings of the object and cooperating teams in the way similar to treating the object. Sea-wave or abyssal stream and an operator or diver are also elements of the system, they are only subjected to different rules.
Features of a human-being as an element of the macrosystem are particularly difficult to define. The problem is addressed to in $[1,2,3,7,8,9,11-14,15,17]$. Attempts to define the human organism as a system are known [4] as well as attempts to describe the influence of the psychical condition [10], or health condition and training on efficiency of acting in the macrosystem. However, they do not provide a well-justified description of the reliability as an element of the analysed macrosystem.

A proposition of description of the human reliability is presented hereafter which leads to the real results of the analyses confirming the well-known truth that a man is often the weakest link of the macrosystem. The proposition is derived from the earlier works $[5,6]$. A reason for commencing the investigation is resignation from treating a human as an element of the macrosystem which is often encountered approach. This can be explained by the lack of a method coherent with the methods of the analyses of the systems.

Human faults can be divided into three groups:

A. Faults made independent of action of the technical system and surroundings. Such faults occur when the system acts correctly and no threats from the surroundings exist. Probability of occurrence of these faults depends on factors such as education or training, age, health condition, fatigue and exhaustion and similar factors dependant on the performed task.

B. Faults dependant on the action of the technical system and threats emitted by surrounding. They arise in the result of stress caused by damages initiating events and impacts of surroundings dangerous for a man.

C. Technical devices are operated in time $T_{e}$ (Fig.1), relatively long comparing to time $\mathrm{T}_{\mathrm{c}}$ suitable for analysis of human 
faults. Time $\mathrm{T}_{\mathrm{e}}$ is typically a few to several years while time $\mathrm{T}_{\mathrm{c}}$ can be a few hours (e.g. time of a one shift, watch, flight etc.). A method of determination of the function defining human reliability $\mathrm{R}_{\mathrm{HE}}(\mathrm{t})$ in the scale of operational time $\mathrm{T}_{\mathrm{e}}$ is given below. The method is based on the simulation of probability $R_{C}$ of not committing a fault by the human in each time interval $T_{c}$ after random time $\mathrm{t}_{1}$. Simulation analysis is performed in the area of systematic and incidental faults taking into consideration the influence of stress caused by undesirable events in the analysed macrosystem.

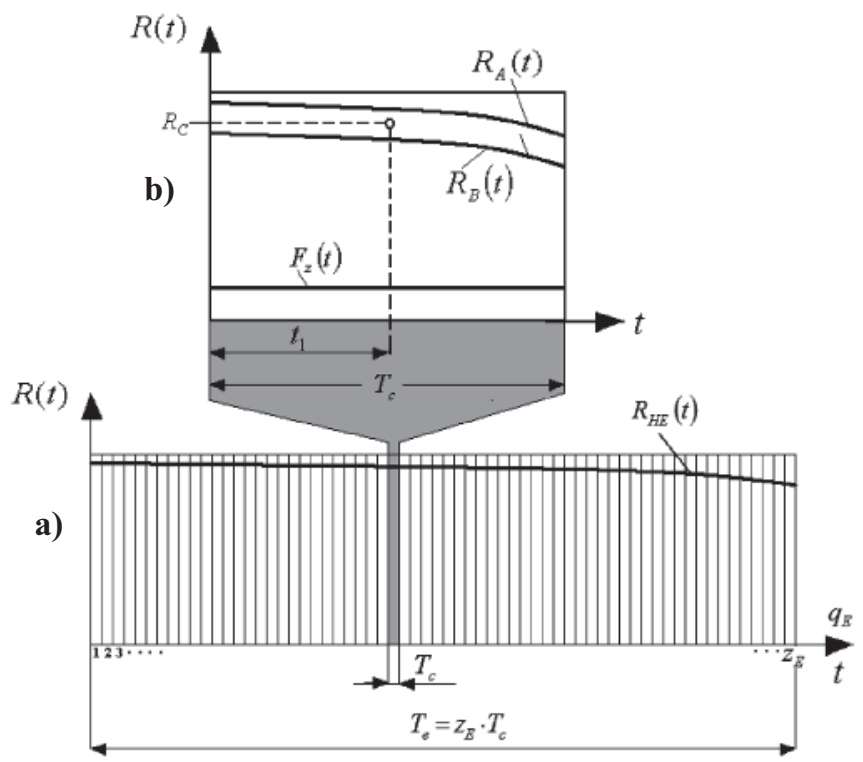

Fig. 1. Principle of analysis of human reliability a) scale of time $T_{e}$ of operating technical system and fault analysis $T_{c}$, b) area of incidental faults

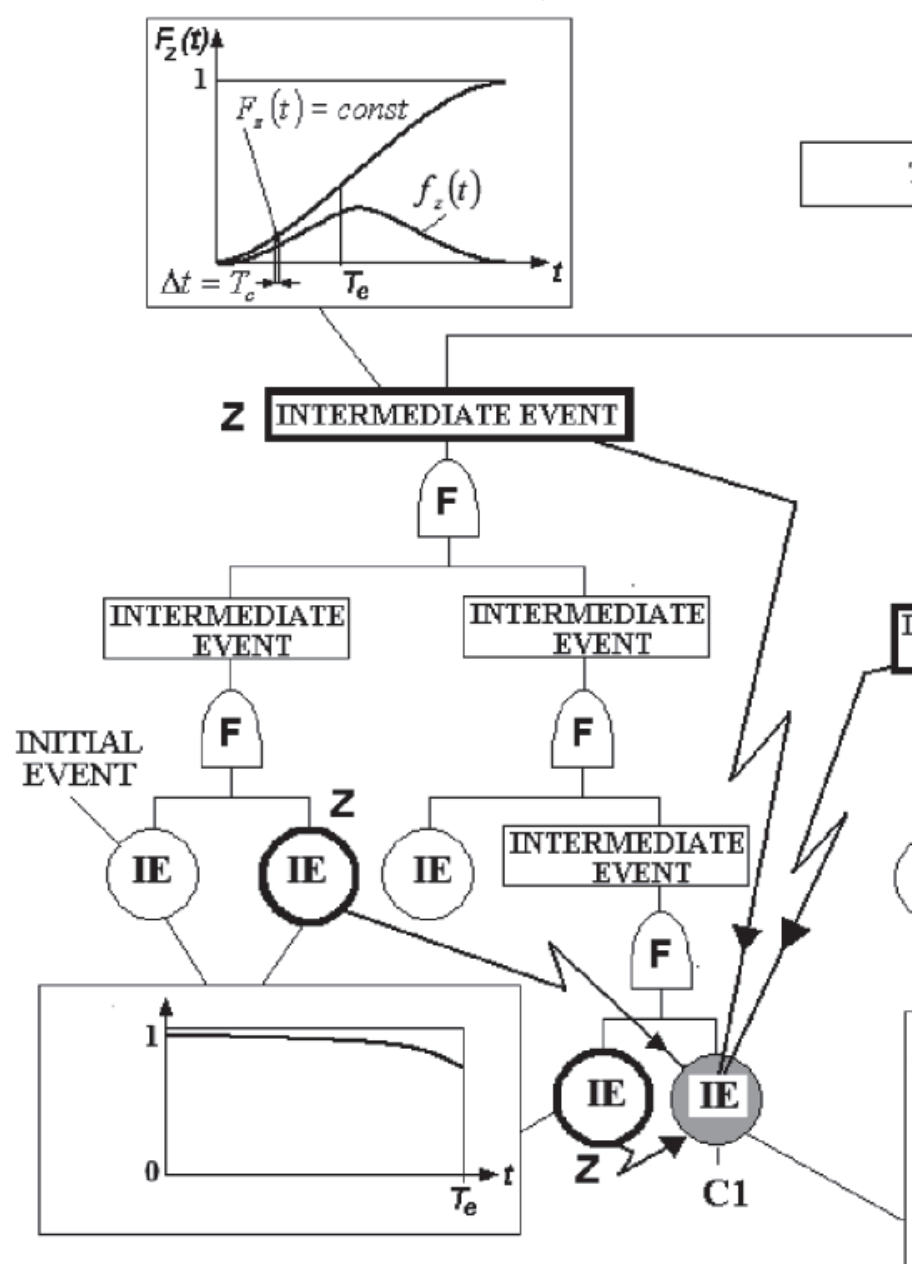

Fig. 2. Principle of action of events generating stress. $\mathbf{I E}$ - initiating events, $\mathbf{F}$ - logical functors, $\mathbf{C} \mathbf{1}$-human fault due to stress, $\mathbf{Z}$ - events generating stress
Let us assume that probability of occurrence of the faults belonging to group $\mathrm{A}$ is given by the distribution function based on corresponding histogram. Cumulative distribution function allows to define reliability function $\mathrm{R}_{\mathrm{A}}(\mathrm{t})$ which yields the probability that a human fault will not occur in the period to required time. The function will be called efficiency function. By assumption, the probability density function of distribution of the faults can be truncated in zero, so the initial value of the cumulative distribution function $\mathrm{F}_{\mathrm{A}}(0)>0$ and efficiency function $R_{A}(0)<1$. It is the effect of occurrence of group $A$ faults already in the beginning of the period of the shift.

The question arises how to determine analogical function $\mathrm{R}_{\mathrm{B}}(\mathrm{t})$ taking into consideration group $\mathrm{B}$ faults. Reaction of a man to stress depends on his individual features. People reacting to stress violently commit more faults qualified to group B. An area can thus be identified where incidental faults due to stress are located. A reason of stress is to be a random event occurring in the technical system or surroundings. It is illustrated by the event tree in Fig. 2 where intermediate events $\mathbf{Z}$ are indicated being the reason of human stress whose fault is one of initiating events IE denoted by C1.

Random distributions of the initiating events presented e.g. in the forms of reliability functions $\mathrm{R}_{\mathrm{IE}}(\mathrm{t})$ of the system elements where the events occur are known. It is thus possible to determine probability density function $\mathrm{f}_{\mathrm{z}}(\mathrm{t})$ of events $\mathbf{Z}$ influencing the human stress (Fig.2). Selected initiating events defined by function can also be considered as such events. Function $\mathrm{f}_{\mathrm{z}}(\mathrm{t})$ can be determined using a computational method - in the case when simple functors are present in the tree or a computer simulation method - in the case when conditions are present in the system prohibiting application of the Boolean algebra. [1]. Functions $\mathrm{f}_{\mathrm{z}}(\mathrm{t})$ and cumulative 
distribution function $\mathrm{f}_{\mathrm{z}}(\mathrm{t})$ are determined in operational time $\mathrm{T}_{\mathrm{e}}$. Probability of occurrence of an event generating stress in given time interval $\Delta \mathrm{t}$ is:

$$
\mathrm{p}_{\mathrm{z}}(\mathrm{t})=\mathrm{f}_{\mathrm{z}}(\mathrm{t}) \cdot \Delta \mathrm{t}
$$

Since time $T_{c}$ of one shift is negligibly small comparing to operational time $\mathrm{T}_{\mathrm{e}}$, it can be assumed $\Delta \mathrm{t}=\mathrm{T}_{\mathrm{c}}$ what means that the probability of occurrence of an event generating stress in the period of one shift given by:

$$
\mathrm{p}_{\mathrm{z}}\left(\mathrm{t}_{1}\right)=\mathrm{f}_{\mathrm{z}}(\mathrm{t}) \cdot \mathrm{T}_{\mathrm{c}}
$$

is constant.

For the purpose of the computer analysis it means that the time increment should be taken not greater than time $\mathrm{T}_{\mathrm{c}}$. Since $\mathrm{T}_{\mathrm{c}}<<\mathrm{T}_{\mathrm{e}}$ it can be assumed that:

$$
\mathrm{p}_{\mathrm{z}}\left(\mathrm{t}_{1}\right)=\mathrm{p}_{\mathrm{z}}=\text { const for } 0<\mathrm{t}_{1} \leq \mathrm{T}_{\mathrm{c}}
$$

Value of the cumulative distribution function for period $0 \div \mathrm{T}_{\mathrm{c}}$ is also constant:

$$
\mathrm{F}_{\mathrm{z}}\left(\mathrm{t}_{1}\right)=\text { const }
$$

Assuming that the event generating stress implies fault due to stress, what corresponds to the absolute stress flexibility, can be given by limit function of stress $R_{B}(t)$. Single event from group $\mathrm{A}$ or $\mathrm{B}$ is enough to cause occurrence of a human error. The function is thus given by:

$$
\mathrm{R}_{\mathrm{B}}(\mathrm{t})=1-\mathrm{R}_{\mathrm{A}}(\mathrm{t}) \cdot\left[1-\mathrm{F}_{\mathrm{z}}(\mathrm{t})\right]
$$

If there is more than one incidental event generating stress the probability range of making fault due to stress increases. If we assume that for occurrence of stress one of the selected events is satisfactory, the limit stress function is written in the following form:

$$
\mathrm{R}_{\mathrm{B}}(\mathrm{t})=1-\mathrm{R}_{\mathrm{A}}(\mathrm{t}) \cdot \prod_{\mathrm{i}=1}^{\mathrm{k}}\left[1-\mathrm{F}_{\mathrm{zii}}(\mathrm{t})\right]
$$

where:

$\mathrm{k}-$ number of events generating stress.

Occurrence of stress does not imply making stress by a human. There is certain probability $\mathrm{p}_{\mathrm{b}}$ of such an event. Let us assume that the probability is proportional to the human flexibility level to stress and that the flexibility can be measured using a scale. Let the scale have range $0 \div \eta$ where:

$$
\eta=R_{A}(t)-R_{B}(t)
$$

The scale can be e.g. 10-grade.

The probability of the event that a given person is flexible to stress at the given grade of the introduced scale can be estimated based on the results of the simulation investigation for a group of persons. Let us assume that the probability is independent of time but depends on the personality. If the random distribution of the stress flexibility e.g. in Fig. 3 is known, the probability can be evaluated:

$$
\mathrm{p}_{\mathrm{b}}=\mathrm{p}_{\mathrm{b}}(\mathrm{t})=\mathrm{f}(\eta) \cdot \Delta \eta
$$

where:

$\Delta \eta=1-$ section of the scale of the stress flexibility.

To evaluate a random value of the human reliability the computer simulation method can be applied. The idea of the method is presented in Fig. 4

The purpose of the simulation is to determine the probability that the fault does not happen in the random period of time $0-\mathrm{t}_{1}$ in the period of human activity in time $T_{c}$ (e.g. first shift). Since cumulative distribution function of stress fault time distribution $F_{B}(t)$ is known - the simulation of time of occurring the event $t_{1}$ can be done using the well-known method of generating random numbers of homogenous distribution $\mathrm{L}_{1}$. Note that the ordinate of cumulative distribution function $\mathrm{F}_{\mathrm{z}}(\mathrm{t})$ (Fig 1b) is different for various periods of time from range $0-T$. Then cumulative distribution function of the distribution of the human flexibility to stress $F(\eta)$ in the range of the scale $\eta$ is applied to sampling of random value of human reliability $\mathrm{R}_{\mathrm{C}}\left(\mathrm{t}_{1}\right)$ using the homogenous distribution (random number $\mathrm{L}_{2}$ ). If the operational period is divided into $\mathrm{z}$ cycles (Fig. 1) with time $\mathrm{T}_{\mathrm{c}}$, it is possible in the way of multiple repetition of the simulation for each cycle to obtain human reliability function $\mathrm{R}_{\mathrm{HE}}(\mathrm{t})$.

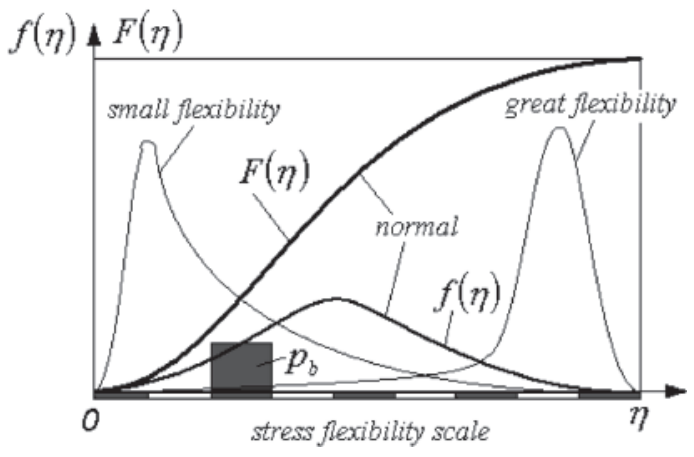

Fig. 3. Typical random distribution of human flexibility to stress

If the human fault is an initiating event (C1 - Fig.2) in the other branch of the event tree than event $\mathbf{Z}$ generating stress the analysis should be first performed in the limited area of the tree so that function $F_{z}(t)$ is determined. It is then possible to evaluate the human reliability. If the situation is contrary and the human fault impacts the random distribution of the events generating stress (Z1-Fig.2), the method of successive approximation can be applied assuming in the first step human reliability function being equal to 1 .

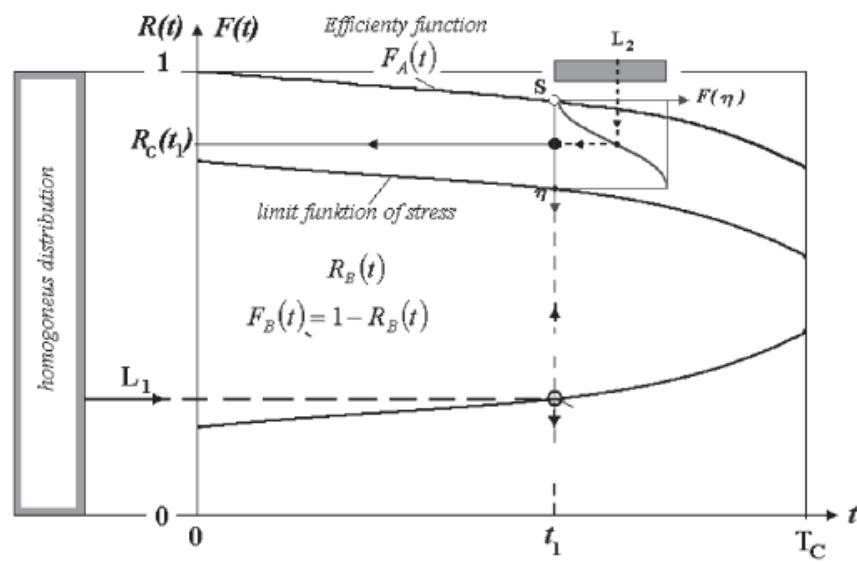

Fig . 4. Principle of computer simulation of single realisation of human reliability

Function of human efficiency and stress function as well as all reliability function of elements of technical system can be described employing the relationship useful for computer analysis [10]:

$$
\mathrm{R}(\mathrm{t})=\mathrm{e}^{\mathrm{K}\left(\frac{\mathrm{t}}{\mathrm{T}_{\mathrm{c}}}\right)^{\mathrm{b}}}-\mathrm{c} ; \mathrm{K}=\ln (\mathrm{a})
$$

where:

a $\quad-$ final value of the efficiency function (for $t=T_{c}$ )

$\mathrm{b}=0 \div 13$ - coefficient determining the curve shape

c $\quad-$ initial value for $\mathrm{t}=0$.

Limit function of stress $\mathrm{R}_{\mathrm{B}}(\mathrm{t})$ can be determined according to Eq. (6) employing Eq. (9). Since Eq. (9) defines reliability 
function $R(\eta)$, cumulative distribution function $F(\eta)$ (Fig.3) can be defined using Eq. (9) as:

$$
\mathrm{F}(\eta)=1-\mathrm{R}(\eta)
$$

Determination of the stress function is easy in the case when the stress generates another initiating event. Then the cumulative distribution function of this event is the cumulative distribution function of the event generating stress.

\section{COMPUTER CODE FOR HUMAN RELIABILITY ANALYSIS}

To present the results of the considerations given above computer code RELBOOL2 was developed. Logical dependencies between the events were limited to the events defined using symbols „AND” and „OR”. Thus code RELBOOL2 analyses only simple trees employing dependencies typical for the Boolean algebra.

Total operational time $T_{e}$ is divided into $\mathrm{z}_{\mathrm{E}}$ time intervals and the time coordinate $t$ is replaced by a coordinate of interval number $\mathrm{q}_{\mathrm{E}}$ (Fig.1). This part of the code provides a possibility of very fast analysis of multi-element but simple fault trees and is obviously applied not only to human reliability analysis. For this analysis an initiating or intermediate event $\mathbf{Z}$ is selected which generates stress and remembers their characteristics $\mathrm{f}_{\mathrm{z}}\left(\mathrm{q}_{\mathrm{E}}\right)$ and $\mathrm{F}_{\mathrm{z}}\left(\mathrm{q}_{\mathrm{E}}\right)$.

In the next part of the code the procedures are launched for the reliability analysis of a human acting in conditions of possibility of stress induced by the intermediate events in the technical system and surroundings. The procedures compute ordinates of limit stress function $\mathrm{F}_{\mathrm{B}}\left(\mathrm{q}_{\mathrm{E}}\right)$ in the operational time loop $\left(\mathrm{q}_{\mathrm{E}}=1-\mathrm{z}_{\mathrm{E}}\right)$ and sample in the range $\mathrm{t}=1 \div \mathrm{T}_{\mathrm{c}}\left(\mathrm{q}_{\mathrm{C}}=1 \div \mathrm{z}_{\mathrm{C}}\right)$

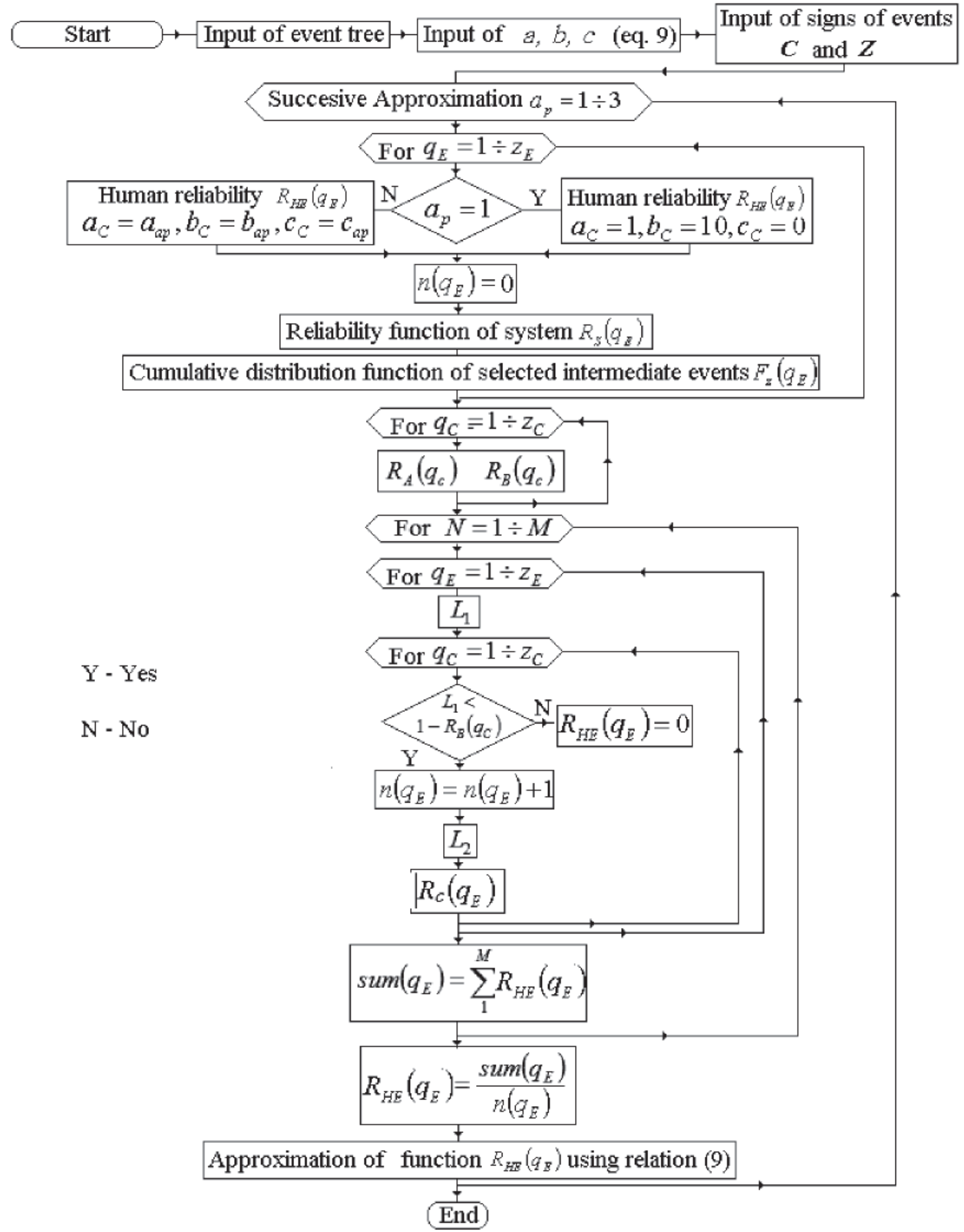

Fig. 5. Flowchart of code RELBOOL2 
time $t_{1}$ of fault occurrence and then sample value $R_{c}\left(q_{E}\right)$ of human reliability. The computations are repeated in the loop: $\mathrm{i}=1-\mathrm{M}$ times, and for each time interval $\mathrm{q}$ the mean value of the reliability obtained from $\mathrm{M}$ simulations. Values $\mathrm{M}=1 \cdot 10^{4}$ or greater are applied to obtain smooth reliability curves.

\section{EXAMPLES OF HUMAN RELIABILITY ANALYSIS}

\section{Example P1}

For clear presentation of applicability of the presented approach a simple example of the system is given (Fig. 6). In the system the divers are lowered in the diving bell using the single hoisting rope $\mathrm{L}$ fixed at the bell with bolt $\mathrm{S}$.

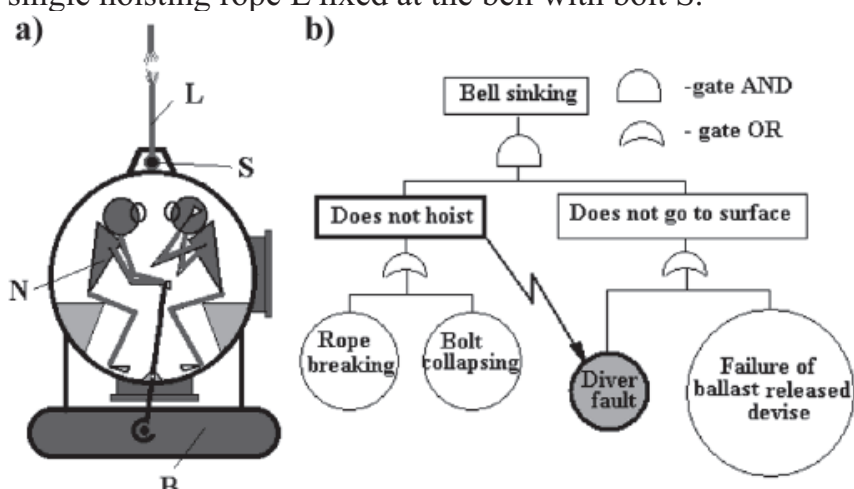

Fig. 6. Example P1 of simple diving system a) scheme of the system, b) fault tree

a)
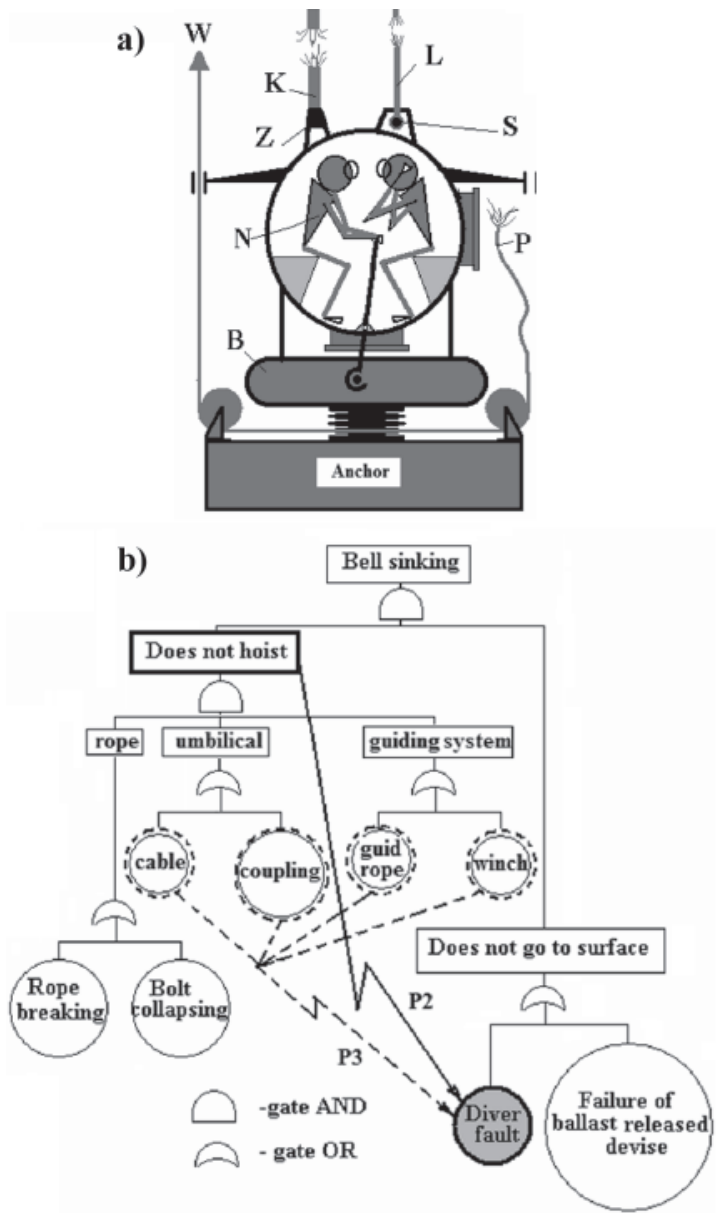

Fig. 7. Complex diving system (example P2 and P3). a) scheme of the system, b) fault tree

In the case of breaking the rope or collapsing the bolt in shear one of the divers (bell operator $\mathrm{N}$ ) must release ballast
B to allow the bell to rise to the surface. The task is performed in stress induced by breaking the rope what can cause the fault and the ballast is not released. The same effect can appear due to failure of the technical subsystem releasing the ballast. The event tree for this scenario is presented in Fig.6a. Intermediate event 1 "DOES NOT HOIST" as denoted as event $\mathbf{Z}$ inducing stress and the fault of diver „N".

The following data were taken for the determination of the reliability function according to Eq. (9):

Rope: $\mathrm{a}=0.95 \mathrm{~b}=5 \mathrm{c}=0$

Bolt: $\quad \mathrm{a}=0.95 \mathrm{~b}=5 \mathrm{c}=0$

Diver: $a=0.95 \mathrm{~b}=5 \mathrm{c}=0.02$ - efficiency function $\mathrm{R}_{\mathrm{A}}\left(\mathrm{q}_{\mathrm{C}}\right)$

Ballast: $\mathrm{a}=0.95 \mathrm{~b}=5 \mathrm{c}=0$ (release system).

\section{Example P2}

For illustration of the influence of the structural quality, the system was analysed presented in Fig. 7. It is a significantly better system as it is equipped with umbilical (cable) $\mathrm{K}$ and guide rope $\mathrm{P}$. The cable hose is fitted to the bell using connection $Z$. Other denotations in the scheme are similar to those used in Example 1. During regular operation the umbilical supplies energy and the other life support means to the diving bell. It is equipped with the internal strands made of carbon fibres which are load-carrying elements allowing to hoist the bell to the surface. Guide rope are normally loaded by the ballast anchor situated on the bed and strained by the controlled force to move the bell correctly if the bell is subject to side hydrodynamic thrust. In the emergency condition the cables hoist the bell with ballast above the water surface. Releasing ballast is definitely the last way to rise the bell in emergency. Thus there are three independent ways to rise the bell using the strands and selfacting rising to the surface.

Let us assume the following scenario: Breaking the loadcarrying cable or the bolt connection with the bell and breaking the umbilical or its coupling and simultaneous (in the same period of time q) breaking the umbilical or failure of the hoisting winch $\mathrm{W}$ make hoisting the bell using the cables impossible. Then diver $\mathrm{N}$ subject to stress makes the fault disabling releasing ballast $\mathrm{B}$ or the ballast release system failure disables self-acting rise to the surface. The fault tree corresponding to this scenario is presented in Fig.7.

The following data were taken for Example 2:

All elemens: $\mathrm{a}=0.95, \mathrm{~b}=5, \mathrm{c}=0$.

Diver: $\quad \mathrm{a}=0.95, \mathrm{~b}=5, \mathrm{c}=0.02-$ efficiency function $\mathrm{R}_{\mathrm{A}}\left(\mathrm{q}_{\mathrm{C}}\right)$.

Elements which appeared in Example 1 have the same reliability.

\section{Example P3}

The data are taken as for Example 2. The scenario has been changed comparing to the Example 2 assuming that the stress is generated not due to one intermediate event ,DOES NOT HOIST" but is an effect of four events: „CABLE” (breaking), "COUPLING", 'GUIDE ROPE" (breaking) and "WINCH". It was thus assumed that the diver does not react with stress to event "DOES NOT HOIST" but reacts with increasing stress to four consecutive events.

Diagrams of the limit stress functions for previously presented examples $\mathrm{P} 1, \mathrm{P} 2$ and $\mathrm{P} 3$ are presented in Fig. 8. The functions are determined for a single cycle in the latest operational period that is for $\mathrm{q}_{\mathrm{E}}=\mathrm{z}_{\mathrm{E}}$. For the remaining periods the area between efficiency and stress functions is less what is reflected by the distribution function curve. (e.g. Fig. 14 curve $\mathrm{P} 1)$. In example $\mathrm{P} 2$ the structure of the system is so reliable, 
that the distribution function of the event influencing stress is close to zero. The effect of this situation is that the efficiency and stress functions are identical. Comparison of examples P1 and P3 is also interesting. It is evident that the assumption of susceptibility to stress caused by as many as four events can eliminate positive influence of structure on human reliability.

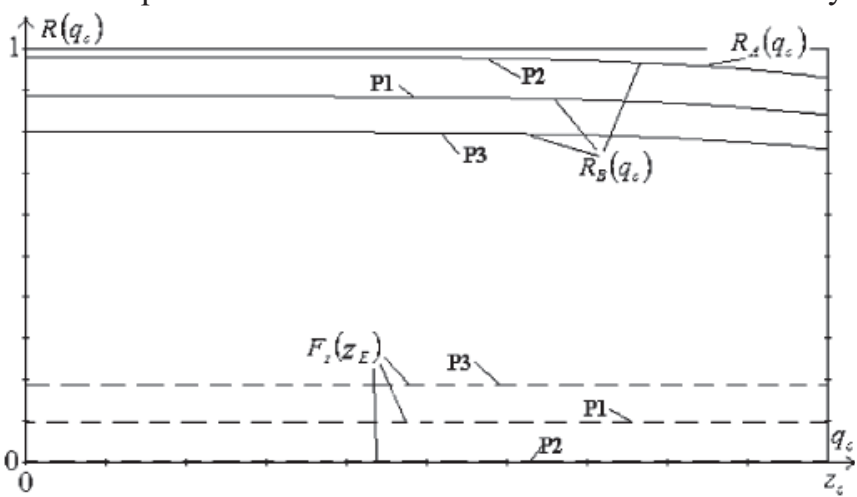

Fig. 8. Limit stress functions for examples $P 1, P 2$ and $P 3$

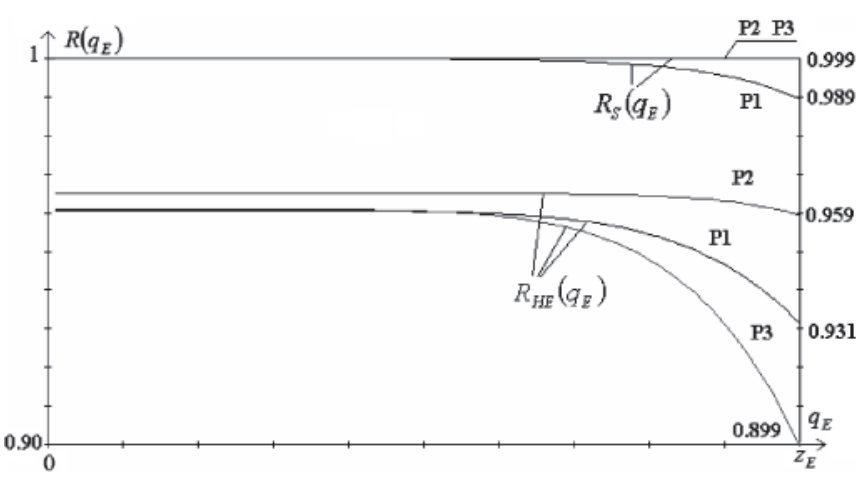

Fig. 9. Functions of human reliability $R_{H E}\left(q_{E}\right)$ and system reliability $R_{S}\left(q_{E}\right)$ for examples $P 1, P 2$ and $P 3$

Functions of human reliability $\mathrm{R}_{\mathrm{HE}}\left(\mathrm{q}_{\mathrm{E}}\right)$ and system reliability $\mathrm{R}_{\mathrm{S}}\left(\mathrm{q}_{\mathrm{E}}\right)$ obtained for the presented examples are given in Fig. 9. The influence of the structure on human reliability and influence of the number of events causing stress on human reliability for the whole operational period.

\section{Example P4}

A transshipment system was considered (Fig. 10) using the crane traveling on the gate bridge. Hitting bumper B with full speed after passing the terminal position is one of the hazards for the safety of transshipment. It can occur if the system of electrical braking EBS or control system does not work. Passing the terminal position can also occur if sensor $\mathrm{S}$ controlling the crane position or the terminal switch ES fails. A system of the emergency braking is designed in which operator OP presses button STOP SB starting mechanical brakes MBS in the case signalization SG informs that the crane passed the terminal position. Operator acts in the stress caused by passing the terminal position or failure of the controller $\mathrm{D}$ and can commit a fault of not pressing button SB on time. Operator's action can be inefficient if button SB is damaged or signalization SG fails.

Function of efficiency of a human and all elements was taken to have identical values as in example P2.

\section{Example P5.}

Structure and event tree and human efficiency function are identical as in P4 while the reliability of other elements was taken to have less values:

$\mathrm{a}=0.8$

$\mathrm{b}=5$

$\mathrm{c}=0$.

Fig. 12, analogically to Fig. 8, presents the limit stress functions and efficiency function for examples P4 and P5. Deterioration of quality of technical elements while the operator efficiency function remains unchanged is observed.

Functions of system reliability $\mathrm{R}_{\mathrm{S}}\left(\mathrm{q}_{\mathrm{E}}\right)$ and human reliability $\mathrm{R}_{\mathrm{HE}}\left(\mathrm{q}_{\mathrm{F}}\right)$ in the whole operational period are given in Fig. 13. It is not only the structure of the technical system which influences the human reliability (examples P1 and P2) but also the quality of the elements. The influence becomes more significant as the operational time increases what results from the distribution function of the damage process presented in Fig. 14.

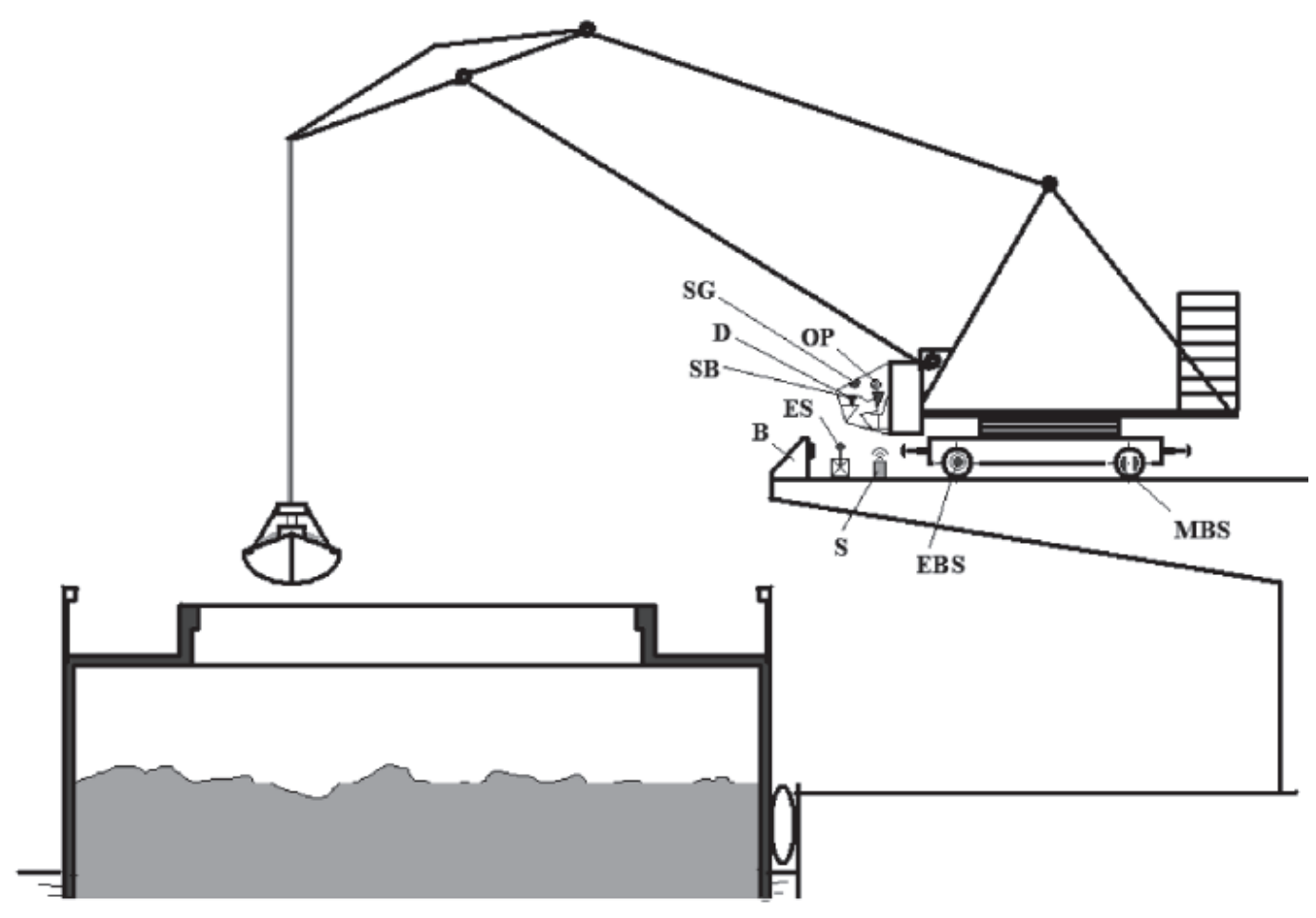

Fig. 10. Scheme of transhipment system 


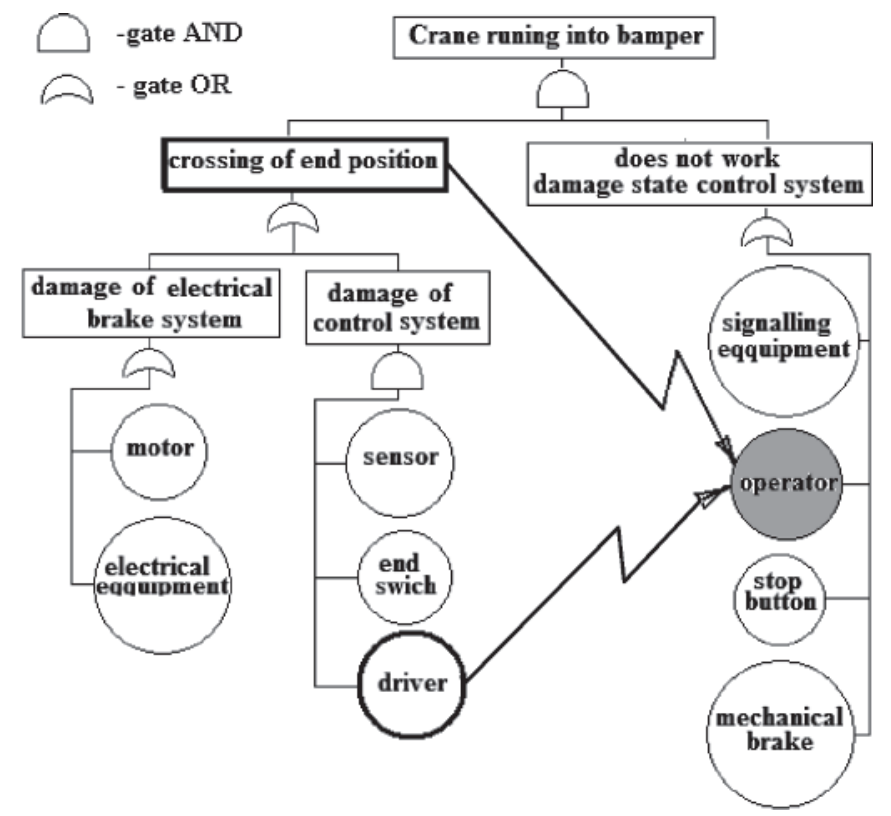

Fig. 11. Damage tree for examples P4 and P5

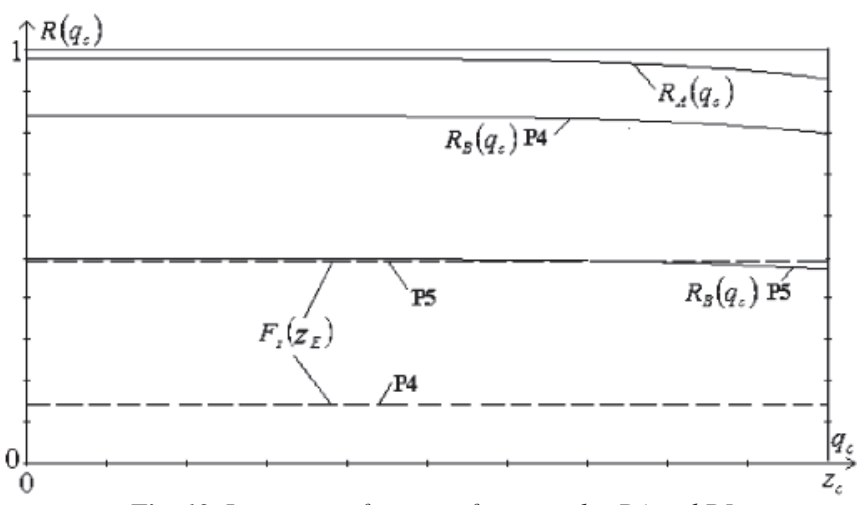

Fig. 12. Limit stress functions for examples P4 and P5

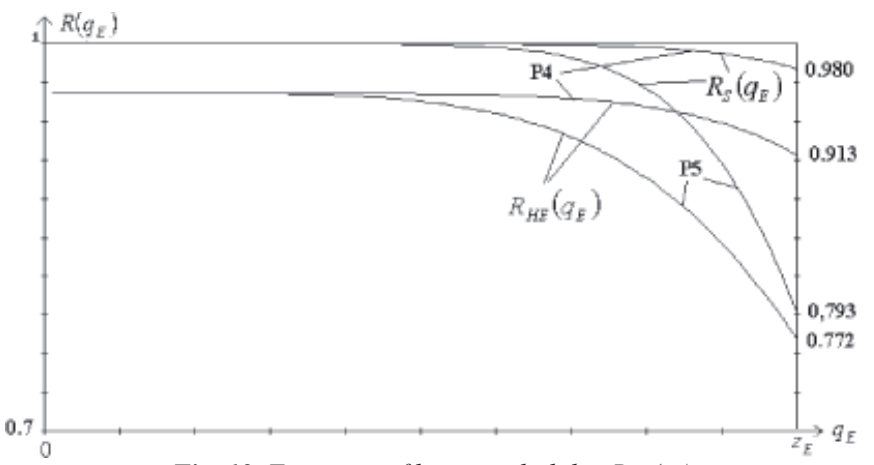

Fig. 13. Functions of human reliability $R_{H E}\left(q_{E}\right)$ and system reliability $R_{S}\left(q_{E}\right)$ for examples $P 4$ and $P 5$

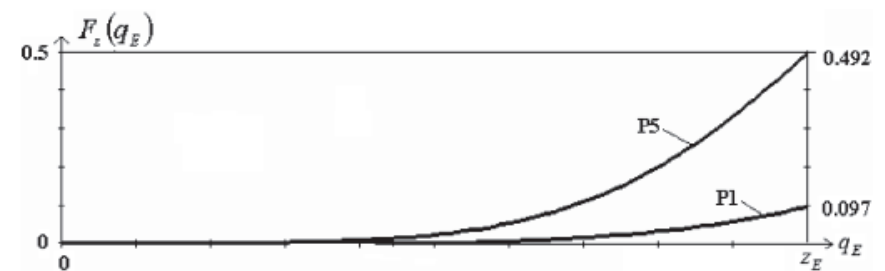

Fig. 14. Cumulative distribution functions of event „DOES NOT HOIST” for examples $P 1$ and $P 5$

\section{CONCLUSIONS}

The proposed method allows to take into account the influence of the technical system ob the human reliability in the reliability analyses.
The human reliability functions based on the analysis of his faults in a short period of time (e.g. one watch) obtained using the presented approach can be referred to the whole system of operation of a technical system in the given macrosystem.

Further research on the function which is referred to as human efficiency function in the present paper is advisable

Application of the proposed approach to the algorithms for simulation computer codes taking into consideration complex dependencies between the events is advisable.

\section{BIBLIOGRAPHY}

1. Bareith A., Borbley S., et.: Treatment of human factors for safety improvements at the pacs nuclear power plants. ESREL'96 - PASM-III, vol.2, Crete, Greece, 1996

2. Bobrowski D.: Mathematical modelling of system technical object-human being. Proceedings of workshop Reliability of "system technical object-human being" (in Polish). KBM PAN Warszawa 1984

3. Dougherty E.M. Jr., Fragola J.R: Human reliability analysis. John Wiley and Sohns, New York, 1998

4. Girtler J., Kitowski Z., Kuriata A.: Safety of ships at seasystem-like approach (in Polish). WKŁ, Warszawa 1995

5. Hann M.: Computerised analysis of reliability and safety of ship machinery and structures subject to rolling (in Polish). "Okrętownictwo i Żegluga" Sp. z o.o., Gdańsk 2001

6. Hann M,. Rosochacki W.: Threats during marine crane operation (in Polish). PMR, Z. 19, 2002

7. Harms-Ringdahl L.: Safety analysis. Principles and practice in occupational safety. Elsevier Applied Science, London, UK, 1993

8. Kosmowski K.T.: Issues of the human reliability analysis in the context of probabilistic studies. International Journal of Occupational Safety and Ergonomics 1995

9. Kosmowski K.T.: Integrated approach to probabilistic modelling and analysis of safety of anthropocentric systems belonging to certain class (in Polish). Proceedings of VI Symposium of Safety of Systems, Kiekrz, 1996

10.Kuriata A.: Selected methods for identification of "personality psychology" (in Polish). ITWL, Proceedings of VI Symposium of Safety of Systems, Kiekrz, 1992

11. Morawski M. Analysis and estimation methods of reliability of human-machine systems (in Polish). Proceedings of Conference Winter School 79, Katowice, 1979

12.Oziemski S.: Efficiency of machine operation. Technical and economical basis (in Polish). Wyd. ITE Radom, 2000

13.Oziemski S.: Searching method for estimation of evaluating quality of machines (in Polish). Proceedings of V Conference Shipbuilding and Marine Engineering, Międzyzdroje, 2000

14.Park K.S.: Human reliability. Elsevier, Amsterdam, 1987

15.Rouse W.B.: System engineering models of human-machine interaction (in Polish). North Holland, New York 1980

16.Semenov J.N.: Managing risk in maritime economics (in Polish). Vol. 1., Wydawnictwo PS, Szczecin 2003

17.Smalko Z., Jaźwiński J.: Influence of human factor on correct behaviour of transportation systems (in Polish). Proceedings of Conference EXPLO-SHIP'99. Międzyzdroje 1999.

\section{CONTACT WITH THE AUTHOR}

Prof. Mieczysław Hann Faculty of Marine Technology, Szczecin University of Technology

Al. Piastów 41

71-065 Szczecin, POLAND

e-mail : kliet@ps.pl 